\title{
Corporate responsibility and the idea of the firm
}

\author{
Laurence Cranmer \\ Associate Fellow, Saïd Business School, University of Oxford, UK.
}

Scholedge International Journal of Management \& Development (ISSN 2394-3378), Vol.02, Issue 10 (2015) p-23-40. Published by: Scholedge R\&D Center [www.theSCHOLEDGE.org] [Email: sijmd@scholedge.org]

This paper was presented at the Society for the Advancement of Socio-Economics (SASE), 27th Annual Meeting, London, 3rd July 2015, and as a seminar at the London Centre for Corporate Governance and Ethics (LCCGE),

Birkbeck, University of London, 25th April 2014, (minor amendments have been made to the paper since these presentations).

(CLaurence Cranmer

\section{Introduction}

An appeal to some version of corporate responsibility has become a strategic issue for business. There are many interpretations of this idea, but it is unlikely that companies can ignore the debate about this issue. Many companies and most global corporations make public claims about their corporate responsibilities in addition to claims about financial outcomes and success. These claims range from informal contributions to public debate, to responses to issues of public concern, to formal reporting on the basis of sets of objectives and targets ${ }^{1}$.

This raises a conceptual question: to what extent, if at all, do claims about corporate responsibility have implications for the idea of the firm. The argument developed in this paper is one attempt to address this conceptual question.

I will start by setting out one version of the idea of the firm and its core or traditional responsibilities, and then work through a series of possible further responsibilities ${ }^{2}$. Each of these further responsibilities will be incorporated into the initial version in order to understand potential implications for the idea of the firm.

The argument in this paper does not assume that this initial version of the idea of the firm is the only possible version, or that the particular dimensions of responsibility described here are the only possible dimensions. However, given this version and these dimensions the paper will consider the kinds of issues that various claims about corporate responsibility would raise for the idea of the firm, and in particular for the boundaries of the firm. The structure of the argument and the specific implications of the responsibilities identified can be assessed separately; the former may continue to

\footnotetext{
${ }^{1}$ One indication of the extent corporate responsibility reporting is suggested in the KPMG International Survey of Corporate Responsibility Reporting 2011. This finds that, 'Ninety-five percent of the 250 largest companies in the world (G250 companies) now report on their corporate responsibility (CR) activities, two-thirds of non-reporters are based in the US.' This suggests that many companies do at least make claims about corporate responsibility. The nature and depth of the these reports needs to be explored further, and is discussed in this KPMG document. In addition, examples of corporate responsibility reports (or related reports) can be easily accessed on most corporate websites, and are collated on websites such as http://www.csrwire.com/

2 The further responsibilities suggested in this paper are drawn from a variety of sources. One public source of the kinds of issues that could be considered further responsibilities is the Global Reporting Initiative (GRI) https://www.globalreporting.org/Pages/default.aspx According to the website, 'GRI provides all companies and organizations with a comprehensive sustainability reporting framework that is widely used around the world.' This framework is used as the basis for some of the CR reports mentioned above.
} 
be useful even if the latter are disputed or incorrect. In addition, the structure of the argument should make it possible to change the content or the ordering of the specific responsibilities while retaining the overall argument.

This paper does not explicitly distinguish between a series of concepts related to the broad idea of corporate responsibility including corporate social responsibility (CSR), sustainability, and corporate citizenship among others. These concepts may refer to different aspects of a firm's responsibilities. For example 'sustainability' is increasingly central to the public claims made by firms, and in many cases refers to a specific set of primarily environmental responsibilities. The issues raised by these various concepts can be discussed further.

The argument developed does not make claims about whether the implications discussed are desirable, even if the arguments about the implications for the firm are accurate. However, the argument does aim to open up some of the issues that these claims would need to address if any of these implications were considered desirable.

This paper is intended as a contribution to a continuing debate and is not a closed argument. It is intended to promote a discussion of the adequacy, the empirical implications, and the ethical implications of the arguments presented, and to stimulate further critical analysis.

Keywords: Corporate Social Responsibility, Corporate Sustainability, Sustainable Business Practices

\section{Responsibility and value creation}

One way to consider the implications of claims about corporate responsibility is to start with a widely used means of conceptualising business activity: the idea of value creation ${ }^{3}$.

On this view the firm can be described as a centre of value creation. Firms are organised for the production goods and services, typically described as products. Firms add value to inputs through a transformation process to generate outputs. Value creation is measured by the financial return on the investment required to produce these outputs. In general, a financial return is generated by the firm meeting the preferences of its customers to whom products are sold. Financial return may be defined as profit or, for many companies, a return on shareholder investment.

It may be argued that claims about corporate responsibility raise issues beyond the firm. On this view, the debate about corporate responsibility may change the legal or policy context in which firms operate, or the preferences of some investors or customers, but not the idea of the firm itself. A standard model of value creation would remain a central means of conceptualising the firm. Ideas about wider corporate responsibility would inform the debate about public policy, regulation and legislation, and about the preferences of investors and customers, rather than the debate about the nature of the firm or the firm's responsibilities.

On another view, it may be argued that the standard model of value creation can be extended to take into account the impact of business activity beyond the creation of products measured by a financial return. This may involve a wider view of business beyond the traditional boundaries of the firm's actions and outcomes, and may involve extended timescales for analysing these actions and outcomes, including the implications for future generations.

\footnotetext{
${ }^{3}$ One discussion of value creation can found in Michael Porter, Competitive Advantage, Simon \& Schuster, 1978. Porter develops a value chain model of generic activities to describe the process of value creation for an individual firm.
} 
This suggests, but does not of course establish, that some wider conception of corporate responsibility at least makes sense based on an extended view of the standard model of value creation. This raises the question of whether this wider conception requires a change to the standard model of the firm or can be accommodated within this standard model.

\section{Responsibility and the firm: an analysis of implications}

On the standard model of value creation firms generate a financial return through any combination of actions and outcomes that are legal within relevant jurisdictions.

This suggests that the actions and outcomes of the firm are bounded by two principles: a financial principle (F) and a legal principle (L).

I will use the idea of a principle to mean a general claim that is appealed to as the basis for multiple reasons for acting. Reflection on reasons for acting may identify the principles that these reasons are based on, and reflection on principles may establish consistency or lack of consistency with reasons for acting. I suggest that part of the content of a principle and of a reason has ethical significance, as well as other forms of significance including rational significance. The idea of reflective equilibrium is one approach to arriving at justifiable reasons and principles. I will not develop the arguments about these views in this paper, but these can be pursued further. ${ }^{4}$

We have identified two principles. However, firms may have multiple purposes (or aims, objectives, missions or similar descriptions) in addition to principles $\mathrm{F}$ and $\mathrm{L}$. We can make a distinction between these purposes and the overall principles that set the boundaries of the standard model of the firm. On this view the firm pursues its purposes within boundaries set by the two principles $\mathrm{F}$ and $\mathrm{L}$.

It may be argued that $\mathrm{F}$ and $\mathrm{L}$ are already demanding principles: operating within these principles involves significant responsibilities before any further responsibilities are proposed. It may be also argued that $F$ and $L$ do not fully describe all of the responsibilities that firms could accept, and in some cases may in fact accept. These views can be assessed in the light of the analysis in this paper.

On this basis, a standard model of the firm may be stated as:

A centre of value creation bounded by a financial principle (F) and a legal principle (L)

This can be simplified as:

\section{A centre of value creation bounded by $F$ and $L$}

The specific responsibilities under $\mathrm{F}$ and $\mathrm{L}$ are complex. $\mathrm{F}$ is relatively informal and will depend on the market context in which the firm operates, and on aspects of $L$. $L$ is relatively formal. The specific

\footnotetext{
${ }^{4}$ It is important at this stage to set out this general view about what I mean by reasons and principles. This version of my view has drawn most recently on T. M. Scanlon, Being Realistic About Reasons, Oxford, 2014. As part of a wider discussion about the more fundamental question, 'How then do we come to know particular non-derivative truths about which things are reasons' (p102) Scanlon suggests that, 'My own answer is that we do this simply by thinking carefully about what seem to us to be reasons, considering what general principles about reasons would explain them, what implications they would have, and considering the plausibility of these principles' (p102). Scanlon also discusses, 'bringing one's particular judgements about reasons and one's general principles about when something is a reason into reflective equilibrium' (p102). This does not do justice to the complexity of Scanlon's arguments, or to the philosophical issues that these arguments raise, including how and whether Scanlon's use of reasons and principles is consistent with the practical use of these concepts in the current paper. However, as a minimum I suggest that this approach to reasons and principles is useful as a working basis for the analysis in this paper.
} 
responsibilities under $L$ will be explicitly codified, although subject to judicial interpretation. The distinction between informal and formal can be developed further.

For $L$, we can describe a range of approaches for applying each of the responsibilities under $L$ to the firm. We will identify an initial three aspects of this, although other aspects can be identified.

First, the firm may apply $L$ through understanding both the content of relevant specific legislation, and the public policy and ethical intentions of this legislation. Or the firm may seek to find the least stringent and least demanding interpretation of the legislation, and may invest in significant research to establish this interpretation and to defend it. Many firms will operate somewhere between these positions. Firms may find that meeting $\mathrm{F}$ requires an approach closer to the latter, however this may change if, for example, shareholders or consumers expect or require an approach closer to the former.

Second, there are likely to be multiple versions of the content of $L$ across jurisdictions. The firm may seek to apply a version of $L$ that is consistent with the least demanding version of $L$ in the jurisdiction from which it originates and across each jurisdiction in which it operates, or seek to apply the most demanding version of $L$ that is available from each of these jurisdictions. In the latter case, the firm may develop internal standards that are consistent with the most demanding version of $L$, and apply these standards across all jurisdictions.

Aspects of the latter approach may apply to standards of for example health and safety, working conditions or pollution. This is may be problematic where there is a different substantive content to $L$. $L$ may be based a different ethical intention across jurisdictions for example in employment laws in relation to women. It may also be problematic where $L$ reflects a context in which it may be difficult to apply the most demanding version of $L$ for example in rates of pay. A strategy that includes global outsourcing or relocation of some or all operations to relatively low wage economies is based on differences in pay rates, among other factors. The firm may consider it to be very demanding to apply the highest wage rates across all jurisdictions. This could also apply to differential pay rates across regions of a single jurisdiction such as the UK.

Third, the firm may seek the most demanding or the least demanding versions of the range of requirements that constitute international law including treaties, charters, and other agreements. The nature and status of international law is more complex and contested than national law, and the various requirements may be open it greater interpretation. Some of the issues raised for the first two aspects will also apply to international law requirements.

The aspects of $L$ discussed so far suggest that firms may adopt a spectrum of views about $L$ from a maximal to a minimal view. On this basis the standard model of the firm may be revised as:

2. A centre of value creation bounded by $F$ and a maximal or minimal view of $L$

The two principles included in (1) describe the responsibilities of the firm using the standard model ${ }^{5}$. Further ideas about corporate responsibility may add further dimensions to this view, and can be

\footnotetext{
${ }^{5}$ This is a simplification or idealisation of a 'standard model' of the firm. For example, the UK Companies Act 2006 sets out the 'general duties of directors'. This includes the following as part of the, 'Duty to promote the success of the company': 'A director of a company must act in the way he considers, in good faith, would be most likely to promote the success of the company for the benefit of its members as a whole, and in doing so have regard (amongst other matters) to - (a) the likely consequences of any decision in the long term, (b) the interests of the company's employees, (c) the need to foster the company's
} 
described as extending the range of actions and outcomes of the firm beyond those measured by a financial return (F), and beyond those that are legally required, allowed or prohibited $(L)^{6}$.

This may result in an extended view of corporate responsibility that is open ended compared to the standard model of the firm. In the standard model value creation (which itself may involve significant indeterminacy) is constrained by the requirement to generate a financial return legally through the production and sale of products.

To describe further corporate responsibilities we can begin with the following claims, each of which depends on wider considerations than those typically considered of direct relevance to the firm. This is an illustrative list and is not exhaustive:

- Extending the relevant preferences beyond customers who purchase products to include other individuals and communities (often described as stakeholders) affected by the firm's actions and outcomes. This is a stakeholder principle (SH)

- Extending the relevant scope of outcomes to include a range of environmental impacts beyond legally required, regulated or prohibited impacts (e.g. pollution) or where no relevant legal constraints apply (e.g. some aspects of carbon emissions). This includes outcomes that may be described as externalities. This is an environmental principle (EN)

- Long term conceptions of value that cannot be easily measured by a financial return, in particular where this includes meeting the preferences of future generations. This is a long term principle (LT)

- Considering the specific context within which the firm operates such as the alleviation of extreme poverty, the requirements of indigenous communities, or impacts on particularly vulnerable or valuable natural environments. This aspect differs from the claims described above because it may only apply in specific contexts. This is a specific extended principle (SE)

We can describe these claims as adding further principles for the firm based on the idea of value creation.

In each case the principles may be refined further. For example, the stakeholder principle (SH) may include considerations relevant to the proper treatment of individuals (a human rights principle, HR)

business relationships with suppliers, customers and others, (d) the impact of the company's operations on the community and the environment, (e) the desirability of the company maintaining a reputation for high standards of business conduct, and (f) the need to act fairly as between members of the company.' http://www.legislation.gov.uk/ukpga/2006/46/part/10/chapter/2 I cannot offer a legal reading of this part of the Act, but it does appear to suggest a wider view of a director's responsibilities than might be assumed by statement (1) in this paper.

${ }^{6}$ One way amongst others of describing much of the literature on corporate responsibility is the attempt to work out the implications of these further responsibilities for the firm. One example is the article Creating Shared Value, Michael Porter and Mark Kramer, Harvard Business Review, January 2011. This develops an interesting approach and argues that, 'The concept of shared value can be defined as policies and operating practices that enhance the competitiveness of a company while simultaneously advancing the economic and social conditions in the communities in which it operates.' The article suggest that, 'Shared value holds the key to unlocking the next wave of business innovation and growth. It will also reconnect company success and community success in ways that have been lost in an age of narrow management approaches, short-term thinking, and deepening divides among society's institutions.' At the same time, 'Shared value focuses companies on the right kind of profits - profits that create societal benefits rather than diminish them.' It suggests that, 'The moment for an expanded view of value creation has come' and that, 'We need a more sophisticated form of capitalism, one imbued with a social purpose. But that purpose should arise not out of charity but out of a deeper understanding of competition and economic value creation. This next evolution in the capitalist model recognizes new and better ways to develop products, serve markets, and build productive enterprises.' There are a range of complex issues here. I am not yet sure about whether this ends up with a view of the firm that has changed the 'standard model' as defined in statement (1) or is an expanded version of this model. 
and those relevant to the flourishing of the wider community of which these individuals form a part (a community development principle, $\mathrm{CD})^{7}$.

The principles may also be combined. For example, environmental impacts such as carbon emissions are typically considered over the long term and as they affect future generations.

We can describe this revised view of the firm's responsibilities as follows, taking these claims into account:

A centre of value creation bounded by bounded by $F$ and a maximal or minimal view of L;

and a further set of extended principles including a stakeholder principle (SH), an environmental principle (EN), a long term principle (LT), a specific extended principle (SE), and other principles; where each extended principle may be refined further, for example $\mathrm{SH}$ into a human rights principle (HR) and a community development principle (CD); and where extended principles may be combined

We can simplify and generalise this view of the firm by grouping all further principles together as a set of extended principles (E). We can then refine the model of the firm as:

A centre of value creation bounded by $F$

and a minimal or maximal view of L;

and extended principles $(\mathrm{E})^{8}$

This can be simplified as:

3. A centre of value creation bounded by $F$

and a minimal or maximal view of $L$;

and $\mathrm{E}$

An extended view of corporate responsibilities such as that described in (3) is subject to imprecise and emerging views about what constitutes the extended principles that bind the firm. The firm conceptualised as a centre of value creation bounded by the two principles $F$ and $L$ can be relatively clearly defined. As discussed above, $\mathrm{F}$ is relatively informal and indeterminate in the sense that some preferences are unknown; however, once preferences are revealed and customers buy products a financial return can be calculated. $L$ is relatively formal and will vary across jurisdictions; however, legislation is explicitly codified, and is created, interpreted and enforced by legislative and judicial institutions.

\footnotetext{
${ }^{7}$ In both cases these principles (HR and CD) suggest limitations to the idea of preferences; so, an idea of rights may be relevant independent of an individual's revealed or articulated preferences. On one view there may also be a conflict between rights, real interests and preferences. My thanks to Nigel Laurie for raising this issue.

${ }^{8}$ There may be a connection between this extension of the standard model in statement (1) and at least one aspect of the argument developed by Colin Mayer in Firm Commitment, Oxford, 2013. In his, 'critique and celebration of the corporation' (p241), Mayer suggests, 'three straightforward adaptations of current arrangements', which are, 'establishing corporate values, permitting the creation of a board of trustees as their custodians, and allowing for time dependent shares' (p247). These adaptations combine to create what Mayer describes as the 'trust firm'. It is important to point out that he stresses the need for, 'diversity of ownership and governance structures' of trust firms (p264). This summary this does not do justice to the range and complexity of the arguments in the book. However, it is possible that working through the conceptual implications of extending the principles that bind the firm, as in this paper, is one way of working out the kinds of 'corporate values' and other changes that Mayer has in mind.
} 
In order to operationalize extended principles (E), firms will need to determine at least the following: clear definitions for each principle; standards by which actions and outcomes can be measured against these principles; and, sources of authority for these definitions and standards.

Definitions and standards may be determined internally by the firm or externally beyond the firm. External sources are consistent with greater objectivity, but may not fully reflect the requirements of the firm. Internal sources may enable the firm to generate principles in areas where these principles are not currently available externally. Internal sources also suggest a greater requirement for the firm to engage in activities for which the firm may not be fully competent.

One example of a broad set of external principles is the Millennium Development Goals backed by the institutional authority of the United Nations $(\mathrm{UN})^{9}$. The Global Reporting Index $(\mathrm{GRI})^{10}$ may provide a more precise basis for specific actions and outcomes. These examples may be too general and wide ranging for a particular firm. Firms may seek more precise external guidance on specific principles. One example is human rights. This may include an appeal to the UN Declaration on Human Rights, and in particular the UN approach to business and human rights ${ }^{11}$. A further example is the appeal to the Intergovernmental Panel on Climate Change (IPCC), also backed by the UN, for a principle covering carbon emissions ${ }^{12}$. National and international governmental sources may be supported or supplemented by guidance from recognised non-governmental organisations, such as Amnesty International in the case of human rights. The authority of these sources of guidance may be contested.

The firm may generate internal extended principles through, for example, a code of ethics or a sustainability charter. Internal sources may in turn draw on external sources as further support for these principles. The firm may also submit itself to external auditing of its internal principles, and of the actions and outcomes that these extended principles cover. Audits may follow a similar process to the legally required audits that form the basis for the financial reports and accounts.

\footnotetext{
${ }^{9} \mathrm{http}: / /$ www.un.org/millenniumgoals/

${ }^{10} \mathrm{https}$ ://www.globalreporting.org/Pages/default.aspx

${ }^{11}$ http://www.ohchr.org/EN/Issues/Business/Pages/BusinessIndex.aspx This is discussed in the UN document Guiding Principles on Business and Human Rights included on the website. I think this is a good example of one attempt to integrate an 'extended principle', as described in this paper, into business practice. This is a complex issue and as the UN document states, 'These Guiding Principles should be understood as a coherent whole and should be read, individually and collectively, in terms of their objective of enhancing standards and practices with regard to business and human rights so as to achieve tangible results for affected individuals and communities, and thereby also contributing to a socially sustainable globalization. Nothing in these Guiding Principles should be read as creating new international law obligations, or as limiting or undermining any legal obligations a State may have undertaken or be subject to under international law with regard to human rights.' With this in mind, it useful to consider one principle: 'Business enterprises should respect human rights. This means that they should avoid infringing on the human rights of others and should address adverse human rights impacts with which they are involved.' The commentary on this principle suggests that, 'The responsibility to respect human rights is a global standard of expected conduct for all business enterprises wherever they operate. It exists independently of States' abilities and/or willingness to fulfil their own human rights obligations, and does not diminish those obligations. And it exists over and above compliance with national laws and regulations protecting human rights. Addressing adverse human rights impacts requires taking adequate measures for their prevention, mitigation and, where appropriate, remediation.'

${ }^{12} \mathrm{http}: / /$ www.ipcc.ch/ The issue of carbon emissions is an example of both the availability of, and the complexity involved in, external guidance on specific principles. The most recent IPCC report Climate Change 2013: the Physical Science Basis appears to have provoked considerable controversy. At the same time, two of Headline Statements from the Summary for Policymakers from the IPCC website state that, 'Warming of the climate system is unequivocal, and since the 1950s, many of the observed changes are unprecedented over decades to millennia. The atmosphere and ocean have warmed, the amounts of snow and ice have diminished, sea level has risen, and the concentrations of greenhouse gases have increased' and that, 'Human influence has been detected in warming of the atmosphere and the ocean, in changes in the global water cycle, in reductions in snow and ice, in global mean sea level rise, and in changes in some climate extremes. This evidence for human influence has grown since AR4. It is extremely likely that human influence has been the dominant cause of the observed warming since the mid-20th century.' http://www.un.org/climatechange/blog/2013/09/27/headline-statements-from-the-summary-for-policymakers/
} 
Internal and external sources of definitions and standards are means by which the firm can define and operationalize potentially open ended principles suggested by an extended view of corporate responsibility.

A further model of the firm may then be refined as:

4. A centre of value creation bounded by $F$

and a minimal or maximal view of $L$;

and $\mathrm{E}$;

with internal and/or external definitions, standards and authority for $E^{13}$

On this view, the actions and outcomes of the firm are bounded by a wider range of principles than $\mathrm{F}$ and L. For these principles to be operationalized they must enter into the reasons for acting of individuals within the firm, and for the reasons to inform the decisions and actions taken by these individuals.

Principles $\mathrm{L}$ and $\mathrm{F}$ may be incorporated into reasons for acting in the following way. Reasons must be legal and, if legal, must enhance the potential financial return for the firm. The interpretation of legality and projections of financial return may be disputed, and legal and financial principles may interact and inform each other in complex ways. However as a minimum $L$ and $F$ set the boundaries of the firm's actions and outcomes.

Extended principles (E) make this situation more complex, even where internal or external definitions, standards and sources of authority have been established. Resolving this complexity will require clarity across at least two linked dimensions: prioritisation and decision criteria.

Prioritisation involves the ordering of principles as the basis for reasons for acting. $L$ and $F$ may be ordered in the following way. All actions must be legal within an idea of the rule of law, so $L$ has priority over $F$. The question arises whether the firm places $E$ (or one of the specific principles within $E$ ) as a priority over $L$ and $F$, or as subordinate to $L$ and F. For example, a human rights principle (HR) as part of $E$ could have priority over $L$ if it requires actions that exceed minimum legal requirements, but are consistent with these requirements.

When the range of principles binding the firm have been prioritised it will be necessary for the firm to establish explicit criteria for the appeal to each principle when an individual is forming reasons for acting and making decisions, including where principles are determined to have equal priority. For example, a human rights principle (HR) may have priority over $L$ and $F$, or two environmental

\footnotetext{
${ }^{13}$ One attempt to provide a systematic basis for one example of the kinds of 'extended principles' suggested may be found in John Gerard Ruggie, Just Business, Norton, 2013. This book provides a valuable account of the thinking behind Ruggie's work on the UN Guiding Principles on Business and Human Rights. Ruggie finds that the debate on business and human rights, 'pitted "mandatory" approaches against "voluntary" ones' and had, 'induced policy stalemate at the international level.' (p78). Ruggie argues that, 'the overriding lesson I drew from the assessment of the two approaches was that a new regulatory dynamic was required.' (p78) He argues that the, 'The Protect, Respect and Remedy (Framework) and the Guiding Principles (GPs) for its implementation aim to establish a common global normative platform and authoritative policy guidance as a basis for cumulative step-by-step progress without foreclosing any other promising longer term developments.' (p81) The Respect element of the Framework provides the basis for a corporate responsibility and so could perhaps be seen as an 'extended principle'. Ruggie provides the following description, 'Let me sum up how I conceptualized the corporate responsibility to respect human rights. It exists independently of and yet complements the state duty to protect. It is defined in terms of the classic human rights meaning of respect: noninfringement on the rights of others, and addressing harms that do occur. Its substantive content consists of internationally recognised human rights. And its scope follows from its definition: actual or potential adverse human rights impacts by an enterprise's own activities or through the relationships connected to those activities.' (p100)
} 
principles, say on carbon emissions and biodiversity, may have equal priority, but may both be subordinate to $H R$, L and $F$.

Decision criteria will include prioritisation, but will also provide a detailed account of what the principle involves and how the principle can be applied to specific cases that are relevant to the firm's operations.

The model of the firm can then be refined as:

A centre of value creation bounded by $F$

and a maximal or minimal view of L;

and $\mathrm{E}$;

with internal and/or external definitions, standards and authority for E;

with all principles prioritised and with decision criteria for these principles

Prioritisation may determine the degree to which the firm can be described as extending corporate responsibility beyond the standard model. A minimal view suggests further principles that bind the firm but which are subordinate to $L$ and $F$, even if the further principles are considered significant. $A$ maximal view suggests that $L$ and $F$ are subordinate to $E$, or to a principle or principles within $E$.

We can refine two further versions of the model of the firm as:

a. A centre of value creation bounded by $F$

and a maximal or minimal view of $L$;

and a minimal view of $\mathrm{E}$;

with internal and/or external definitions, standards and authority for $E$;

with $E$ as significant but subordinate to $L$ and $F$;

with all other principles prioritised and with decision criteria for these principles

b. A centre of value creation bounded by $F$

and a maximal or minimal version of $L$;

and a maximal view $\mathrm{E}$;

with internal and/or external definitions, standards and authority for E;

with $L$ and/or $F$ subordinate to $E$ or a part of $E$;

with all other principles prioritised and with decision criteria for these principles

(a) and (b) may be combined as:

5. A centre of value creation bounded by $F$

and a minimal or maximal view of $L$;

and a minimal or maximal view of $\mathrm{E}$;

with internal and/or external definitions, standards and authority for $\mathrm{E}$;

with all principles prioritised and with decision criteria for these principles ${ }^{14}$

\footnotetext{
${ }^{14}$ In a wide ranging analysis, David Vogel in The Market for Virtue, Brookings, 2006, reaches the broad conclusion that the direct impact of corporate responsibility on the activities and impact of firms is limited. Vogel cites a number of examples of impacts, but these are greatly outweighed by other factors. This would suggest that most firms most of the time are bound by principle $\mathrm{L}$ and $\mathrm{F}$, with aspects of $\mathrm{E}$ affecting firms in specific situations and usually as a subordinate principle. Vogel's analysis also suggests that $\mathrm{E}$ appears to collapse into $\mathrm{F}$ where it has an impact on for example corporate reputation. This view is summed up in a discussion of the problems with the business case for CSR, 'We are now in a better position to explain why the numerous studies that seek to correlate corporate financial and social performance have produced such inconclusive results. One reason is that the social and environmental practices of the vast majority of companies have not had any demonstrated effects on their
} 
One view of corporate responsibility may suggest that only (b) above presents a view of the firm that is significantly different from the standard model as described in (1). On this view (a) shows that the firm is bounded by $\mathrm{F}$ and $\mathrm{L}$, and that only after its actions and outcomes are determined by these principles are further principles ( $E$ ) appealed to as reasons for acting. However, if $E$ is considered significant and demanding then both minimal and maximal views of $E$ can be considered as extensions of corporate responsibility.

One concern about minimal views of corporate responsibility is that if $E$ is subordinate to $L$ and $F$ it will not, in fact, have any significant impact on reasons for acting and on the firm's actions and outcomes.

A further concern is that $E$ is only appealed in cases where it supports $L$ and $F$ and does not operate as an independent principle. For example, aspects of $E$ may be expressed in the preferences of investors or customers, so appeal to E collapses into a sophisticated appeal to F. Or, aspects of E may suggest emerging or potential changes to $L$, so appeal to $E$ collapses into a strategic and anticipatory appeal to $L$, even if in advance of current requirements under $L$.

To take these concerns into account, the model of the firm can be refined as:

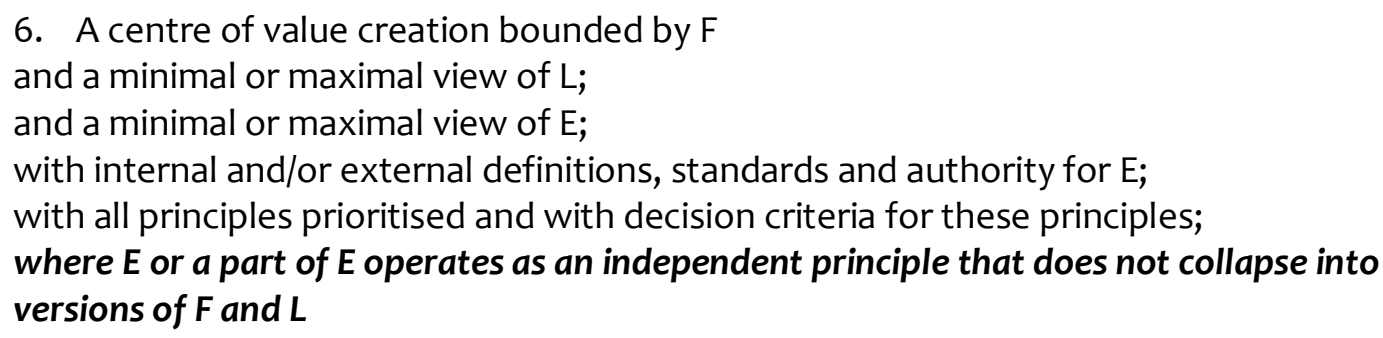

The analysis so far may suggest changes to the overall role of the firm as a social and economic institution (we can summarise this as the role of the firm). A minimal view of E described in (a) above and included in (6) supports the view that even small changes in the basis upon which the firm operates are of interest, and that these changes may suggest a revised model of the firm. A maximal view of $E$ described in (b) provides grounds for suggesting a revised model of the firm. Any such change to the basis upon which the firm operates suggests at least some change to the role of the firm.

The standard model in (1) limits the role of the firm to value creation bounded by $\mathrm{F}$ and $\mathrm{L}$. From the point of view of the firm this may provide a practical description of the firm's actions and outcomes. However, from the point of view of the local and global community within which the firm operates, this role may also include a wider recognition of the utility of all firms operating on an individual basis of value creation bounded by $F$ and $L$. For example, $F$ generates wealth and $L$ sustains the rule of law, and both $\mathrm{F}$ and $\mathrm{L}$ may support wider principles such as freedom and autonomy. This recognition may in turn be reflected in the firm's view of its social and economic role.

sales. Nor have their responses to civil regulation affected their ability to hire and retain motivated an competent employees. Most critically, remarkably few firms have been rewarded or punished by the financial markets for their social performance. And those few that have are not sufficiently numerous or important to affect the results of statistical studies that correlate corporate virtue with financial performance. Of the myriad factors that affect corporate earnings, CSR remains, for most firms most of the time, of marginal importance. Nonetheless it is clear that even if the bottom-line costs and benefits of CSR are difficult to measure and are rarely material to investors, many firms act as if CSR matters. How can we account for this?' (p73, italics in original) 
So, a narrow view of the role of the firm may be limited to a direct appeal to $F$ and $L$, with no reference to claims about utility. A wide view of this role may appeal to $\mathrm{F}$ and $\mathrm{L}$, but with an explicit reference to $\mathrm{F}$ and $\mathrm{L}$ as sustained by claims about utility.

An extended view of corporate responsibility may suggest that some aspects of a wide view are internalised by the individual firm. A minimal view of the role may now incorporate the wide view of value creation, and make an explicit appeal to claims about the utility of $F$ and $L$. A maximal view of the role may make this appeal, and also make claims about the utility of $\mathrm{E}$ or part of $\mathrm{E}$.

The model of the firm can be further refined as:

7. A centre of value creation bounded by $F$

and a minimal or maximal view of $L$;

and a minimal or maximal view of $\mathrm{E}$;

with internal and/or external definitions, standards and authority for E;

with all principles prioritised and with decision criteria for these principles;

where $\mathrm{E}$ or a part of $\mathrm{E}$ operates as an independent principle that does not collapse into

versions of $\mathrm{F}$ and $\mathrm{L}$;

where the role of the firm appeals to the utility of $F$ and $L$ (minimal view), or to the utility of $F$, $L$ and $E$ or part of $E$ (maximal view)

This model of the firm describes aspects of responsibility that extend beyond the boundaries of the firm described in (1). However it may be argued that even in (7) any direct responsibility for the firm's actions and outcomes is located primarily within the boundaries of the firm suggested by (1). On this view, the further responsibilities suggested by, for example, E or by wider views of utility do extend beyond these boundaries but refer primarily to the more or less direct actions and outcomes of the firm.

Further responsibilities for a firm's actions and outcomes that are clearly beyond the boundaries suggested by (1) may involve responsibilities for the firm's supply chain (or supply network). One view of a responsibility for an aspect of the supply chain is a firm taking responsibility for at least some of the actions and outcomes of a supplier to that firm where the supplier is a legal entity distinct from the original firm. The legal separation will include a distinction between employees and contractors, and between in-house and out-sourced activities. A definition along these lines may also be used to consider responsibilities for partners and other collaborators, and for customers of the firm. We will consider suppliers at this stage.

We can identify three initial dimensions of supply chain responsibility, although this is not an exhaustive or comprehensive account. The content of these potential responsibilities may be similar to, and may overlap with, E.

First, the foundations of supply chain responsibility are based on building reliable knowledge of the supply chain through mapping and analysis. This will establish the provenance of supplied products, for example raw materials or components, through multiple supply chain tiers. It will also provide a basis for understanding the actions and outcomes of all suppliers across these tiers. We can describe this first dimension as supply chain knowledge.

Second, the nature of the relationship between the firm and the supplier, and the type of supplier, may vary widely and involve very different potential responsibilities. For example, the relationship between two firms of similar size, that originate and operate in the same developed economy, that 
each have other significant customers and suppliers, and that are co-located, is very different to the relationship between a powerful firm in a developed economy and a smaller and financially weaker supplier from an emerging and geographically distant economy. We can describe the former as a peer supplier and the latter as a dependent supplier with a spectrum of types of relationship in between, recognising that this spectrum does not exhaust the complex range of relationships. We can describe this second dimension as supply chain visibility.

Third, the firm may engage in various of types of management activity to discharge even minimal supply chain responsibility including: providing public information about the supply chain possibly including some analysis of the actions and outcomes of suppliers; developing supplier relationships; and, in depth investigation of supplier actions and outcomes along similar lines to those deployed by the firm to investigate its own actions and outcomes. The latter example may include independent monitoring of supply chain activities, certification of suppliers and supplied products, and decisions made by the firm to cease working with suppliers that do not meet standards. We can describe this third dimension as supply chain management.

With this discussion of supply chains in mind, the model of the firm can be refined as:

8. A centre of value creation bounded by $F$

and a minimal or maximal view of $L$;

and a minimal or maximal view of $\mathrm{E}$;

with internal and/or external definitions, standards and authority for E;

with all principles prioritised and with decision criteria for these principles;

where $\mathrm{E}$ or a part of E operates as an independent principle that does not collapse into

versions of $\mathrm{F}$ and $\mathrm{L}$;

where the role of the firm appeals to the utility of $F$ and $L$ (minimal view), or to the utility of

$\mathrm{F}, \mathrm{L}$ and $\mathrm{E}$ or part of $\mathrm{E}$ (maximal view);

where the firm establishes supply chain knowledge as a basis for supply chain visibility of peer suppliers (minimal supply chain responsibility), or supply chain management of all peer and distant suppliers (maximal supply chain responsibility)

The model of the firm considered so far refers primarily (although not exclusively) to responsibilities for the actions and outcomes involved in the creation of products. We can also consider the firm's responsibilities for the use of revenue and profit generated by the sale of these products. We will consider two dimensions in the first instance: payment of tax, and the distribution of revenue and profit.

On the issue of tax, a firm may develop approaches across a spectrum from a maximal approach to paying tax to legitimate authorities, to a minimal approach based on complex measures to reduce or avoid payment of tax. For this analysis 'tax' refers primarily to taxes on profits (for example, corporation tax) but may include other taxes as well (for example, value added tax).

We can assume for this argument that the firm is based on at the least standard model in (1) and so the approach it adopts remains within L. The standard model suggests that the firm may choose to maximise $F$ while operating within a minimal interpretation of $L$.

The question of tax avoidance arises because of the complexity of $L$ as it applies to tax liabilities and to the legitimate company structures that may maximise or minimise these liabilities. This is a complex issue within a single jurisdiction. It becomes more complex because of the variations in $\mathrm{L}$ across jurisdictions, the multiple jurisdictions that multinational companies operate across, and the 
multiple legitimate structures that these companies may adopt. The responsibility to be prepared to pay some tax is typically included in the content of principle $L$, even if $L$ in fact requires the payment of no tax in some circumstances.

We can link the payment of tax to E. For example, the firm may seek to maximise the payment of tax as a means of distributing profits to public authorities that may, in general, pursue $E$ or part of $E$ through public policy. Elements of $E$ are likely to provide the environment of institutions and infrastructure for the firm's activities and its ability to create value, for example through the provision of a legal system, transport networks and an educated workforce.

In some circumstances payment of tax may support democratic government or emergent democratic governments and so meet further elements of $E$. This may form part of the wider analysis of jurisdictions within which a firm may seek to invest, in this case as an analysis of the uses tax revenues. This may inform the firm's decisions about investment. The implications of these links to principle E can be developed further.

The complexity of corporate taxation means that it is difficult to calculate how much tax a firm has a responsibility to pay. One way to work through this issue is for the firm to create an explicit policy position on taxation that would include amongst other elements: an interpretation of the relevant parts of L; how profit is calculated; the reasons for various company accounting practices and structures; and, how these elements apply across multiple jurisdictions. An addition to the policy position could include an estimate of the proportion of overall profit to be paid in tax, however this may be difficult to estimate and will in turn depend on how profits are calculated. An explicit policy position on tax would enable the firm to provide a public justification for taxes that are paid, even though on this basis the actual amount of tax paid by any firm remains open.

The model of the firm may then be refined as:

9. A centre of value creation bounded by $F$

and a minimal or maximal view of L;

and a minimal or maximal view of E;

with internal and/or external definitions, standards and authority for $\mathrm{E}$;

with all principles prioritised and with decision criteria for these principles;

where E or a part of E operates as an independent principle that does not collapse into

versions of $\mathrm{F}$ and $\mathrm{L}$;

where the role of the firm appeals to the utility of $F$ and $L$ (minimal view), or to the utility of

$\mathrm{F}, \mathrm{L}$ and $\mathrm{E}$ or part of $\mathrm{E}$ (maximal view);

where the firm establishes supply chain knowledge as a basis for supply chain visibility of peer suppliers (minimal supply chain responsibility), or supply chain management of all peer and distant suppliers (maximal supply chain responsibility);

with an explicit policy position on taxation, showing how company structures and accounting practices have been arrived at, with reference to $L$ and possibly to elements of $E$

The second issue identified above is the distribution of revenue and profit. The firm will decide on the payments made to employees, shareholders, suppliers, and other commercial stakeholders based, as a minimum, on a combination of $L$ and $F$ in the standard model in (1).

The firm may decide to develop further principles supported by processes and structures to operationalize the financial support for some of the principles within $\mathrm{E}$. We can make a distinction between internal and external distribution of revenue and profit. 
The principles for determining the distribution of revenues and profits internally within the firm, in particular to employees and owners, may include: minimum incomes; benefits such as holidays, health insurance and maternity/paternity leave; profit sharing; ratios of lowest to highest remuneration; executive remuneration; levels and criteria for bonus payments; and, policies on redundancy. We can describe these as internal distribution principles.

The firm may distribute profits externally to specific institutions or to support specific activities. This includes discretionary giving through sponsorship, charitable donations or non-commercial or partially commercial investment. This may be institutionalised as a structural feature of the firm based on a tithe principle or equivalent. A further development of this approach may include the distribution of a defined proportion of profits to a Trust or equivalent institutional arrangement set up by the firm but independent of the firm's financial interests. The Trust disperses funds to support external institutions or activities.

We can combine these examples and refine the model of the firm as:
10. A centre of value creation bounded by $F$
and a minimal or maximal view of $L$;
and a minimal or maximal view of E;
with internal and/or external definitions, standards and authority for $\mathrm{E}$;
with all principles prioritised and with decision criteria for these principles;
where E or a part of E operates as an independent principle that does not collapse into versions of $\mathrm{F}$ and $\mathrm{L}$;
where the role of the firm appeals to the utility of $F$ and $L$ (minimal view), or to the utility of
$\mathrm{F}, \mathrm{L}$ and $\mathrm{E}$ or part of $\mathrm{E}$ (maximal view);
where the firm establishes supply chain knowledge as a basis for supply chain visibility of peer suppliers (minimal supply chain responsibility), or supply chain management of all peer and distant suppliers (maximal supply chain responsibility);
with an explicit policy position on taxation, showing how company structures and accounting practices have been arrived at, with reference to $L$ and possibly to elements of $E$;
where structures and processes for the internal and external distribution of profits and revenues have been established, and may operationalize financial support for $E$

This model of the firm suggests some changes to the ways in which the firm operates. In order for the firm to operate on a minimally revised basis some internal firm changes may be required to support individuals as they make decisions that operationalize aspects of the revised model.

This may be particularly relevant in market environments where other firms are operating on the basis of the standard model of the firm described in (1). The competitive requirements for operating in such markets may make it difficult to sustain a revised view of the firm if this is not supported by structural and process changes within the firm. The following suggests a series potential changes. As with the examples of extended principles, this is not exhaustive and other changes may be identified.

First, the firm's Board, executives and other senior managers will need an opportunity to discuss and agree the implementation of the revised model of the firm. This will include any further corporate responsibilities, the principles that these responsibilities are based on, and any prioritisation and decision criteria involved. These principles will inform the strategic reasons for acting of senior managers. 
Second, any revised strategic reasons for acting may require shareholder and other investor support. In some cases this may be a legal requirement to ensure that the firm's managers are fulfilling their fiduciary duties to shareholders. It may be argued that all changes to the responsibilities of the firm will eventually require changes to $L$ if these changes are to become a stable and sustainable part of the firm's operations. This issue can be developed further. ${ }^{15}$

Third, all employees and other relevant staff will need an opportunity to discuss and understand the implementation of the revised model of the firm and the further responsibilities and principles that this involves. This will inform the operational reasons for acting for all staff, including the senior managers identified above.

Fourth, processes and structures within the firm will require changes in order to be consistent with, and supportive of, a revised model of the firm. The standard model of value creation in (1) is supported by a range of complex processes designed to support the firm's actions and outcomes bounded by $L$ and $F$. An extended view of corporate responsibility may require revised processes bounded in part by $\mathrm{E}$ and other aspects of the revised model.

The changes discussed support a refined model of the firm, but also form part of that refined view, as:

11. A centre of value creation bounded by $F$ and a minimal or maximal view of $L$; and a minimal or maximal view of $\mathrm{E}$; with internal and/or external definitions, standards and authority for E; with all principles prioritised and with decision criteria for these principles; where E or a part of E operates as an independent principle that does not collapse into versions of $\mathrm{F}$ and $\mathrm{L}$; where the role of the firm appeals to the utility of $F$ and $L$ (minimal view), or to the utility of $\mathrm{F}, \mathrm{L}$ and $\mathrm{E}$ or part of $\mathrm{E}$ (maximal view); where the firm establishes supply chain knowledge as a basis for supply chain visibility of peer suppliers (minimal supply chain responsibility), or supply chain management of all peer and distant suppliers (maximal supply chain responsibility); with an explicit policy position on taxation, showing how company structures and accounting practices have been arrived at, with reference to $L$ and possibly to elements of $E$; where structures and processes for the internal and external distribution of profits and revenues have been established, and may operationalize financial support for $\mathrm{E}$; where strategy, shareholder/investor support, operations, and processes are consistent with a revised model of the firm

The changes above are suggested to enable a firm to operate on even a minimally revised basis. As suggested above, it may be difficult to sustain these changes in a market context in which other firms, including competitors, are operating on the basis of the standard model in (1).

If these changes result in a positive change in $\mathrm{F}$ then even in a market context based on the standard model, the firm may be in a position to sustain operating on a revised basis. In this case, changes in customer and investor preferences suggest that the firm is in fact operating on the basis of (1), but with changes to $\mathrm{F}$ and in some cases the expectation of future changes to $\mathrm{L}$.

\footnotetext{
${ }^{15}$ Thanks to Nigel Laurie for raising this issue
} 
If the changes do not result in a positive change in $\mathrm{F}$, or are difficult to sustain for other reasons, the firm may seek to change the market context itself. ${ }^{16}$ We can identify two broad approaches through which this may be achieved, although other approaches are possible.

First, the firm may support or develop voluntary market or industry standards. For these to be effective they will require the support of all or most firms within a market or industry sector, and across all or most jurisdictions in which these firms operate. As a minimum this is likely to include the support of the largest and most significant firms in the market or industry on the basis that smaller firms may follow. The most effective standards would cover all markets and sectors and be endorsed by all relevant firms. Standards of this kind may be developed in collaboration with national governments, international governmental organisations, and recognised non-governmental organisation such as those discussed in the context of external sources of authority for $\mathrm{E}$. These standards may incorporate aspects of public policy but in this context are distinct from legislation and regulation derived from legislation, and so are not included as part of L. ${ }^{17}$

Second, firms may work to change $L$ and to change aspects of $F$ in part through changes to $L$. These changes may include some of the areas discussed above and can be summarised as aspects of $E$. Firms may seek to make changes to $L$ in a single or a group of jurisdictions or may seek to change aspects of international law or articles considered similar to international law such as treaties and global agreements. The impact of these changes in multiple national jurisdictions, in groups of jurisdictions, or internationally may be sufficient to change $L$ for most firms.

This approach will require significant investment by the firms involved. Firms may have developed experience of influencing and participating in shaping $L$ through lobbying activities aimed at improving the conditions for achieving $F$ through changes to $L$. It may be argued that all changes to $L$ as a result of lobbying directly to improve $F$, or to incorporate aspects of $E$ in $L$, will have the effect of improving $F$ in the long run. The scope and limits of justified lobbying activity can be considered as part of an analysis of pluralist democracy, including the analysis of the scope and limits of firms as a legitimate interest group acting individually or collectively. We can describe the distinction between the two activities as follows. Firms seeking to change $L$ to improve $F$ can be described as lobbying. Firms seeking to change $L$ in order to incorporate aspects of $E$ can be described as engaging in public policy participation. This distinction becomes problematic where changes to $L$ that incorporate $E$ improve $\mathrm{F}$ in the long run.

The criteria for public policy participation will need to be established. The distinction between this public policy participation and lobbying will from a central part of these criteria, and the criteria are likely to be demanding for firms. One route may be to use an idea of public reasoning.

This suggest a further refinement to the model of the firm as:

12. A centre of value creation bounded by $F$ and a minimal or maximal view of $L$; and a minimal or maximal view of E;

\footnotetext{
${ }^{16}$ David Vogel argues for something like this approach, largely because he does not think that CSR has a had a significant effect on the responsibilities and activities of firms. He suggests that, 'The important complementary relationship between civil and government regulation suggests that the definition of a responsible corporation needs to be expanded. Corporate responsibility should be about more than going "beyond compliance"; it must include efforts to raise compliance standards'. David Vogel The Market for Virtue, Brookings, 2006, p171

${ }^{17}$ This is sometimes referred to as soft law.
} 
with internal and/or external definitions, standards and authority for E;

with all principles prioritised and with decision criteria for these principles;

where $\mathrm{E}$ or a part of E operates as an independent principle that does not collapse into

versions of $\mathrm{F}$ and $\mathrm{L}$;

where the role of the firm appeals to the utility of $F$ and $L$ (minimal view), or to the utility of

$\mathrm{F}, \mathrm{L}$ and $\mathrm{E}$ or part of $\mathrm{E}$ (maximal view);

where the firm establishes supply chain knowledge as a basis for supply chain visibility of peer suppliers (minimal supply chain responsibility), or supply chain management of all peer and distant suppliers (maximal supply chain responsibility);

with an explicit policy position on taxation, showing how company structures and accounting practices have been arrived at, with reference to $L$ and possibly to elements of $E$;

where structures and processes for the internal and external distribution of profits and revenues have been established, and may operationalize financial support for $\mathrm{E}$; where strategy, shareholder/investor support, operations, and processes are consistent with a revised view of the firm;

where the firm supports or develops voluntary market or industry standards, and/or participates in changes to $L$, and where the latter meets the criteria for public policy participation

\section{Concluding remarks}

The paper opened with a conceptual question: to what extent, if at all, do claims about corporate responsibility have implications for the idea of the firm.

The analysis started by suggesting a standard model of the firm as: a centre of value creation bounded by $F$ and $L(1)$.

The standard model was revised by adding further responsibilities. These are combined as a refined model of the firm in (12).

Further dimensions of potential corporate responsibilities to be analysed may be identified, and some examples are suggested below:

- Establishing the criteria for public policy participation, possibly involving an idea of public reasoning

- Further dimensions of $\mathrm{E}$, for example the use of various forms of personal information generated by social media and other forms of digital media, and the nature of advertising in particular as this relates to specific demographic groups

- Consideration of whether or not particular questions of responsibility are raised by the actions and outcomes of banks and other financial institutions

- Property ownership as this applies to share ownership, and wider questions about the public and the private

The analysis so far suggests that an extended view of corporate responsibility involves a refined model of the firm, as described in (12). This may have both empirical and ethical implications.

Empirical implications at the level of the firm include the extent to which individual firms are in fact operating on the basis of the refined model, or on the basis of elements or adaptations of this model. 
Empirical implications at the level of markets include the overall impact on welfare and utility if some or all firms adopt this model, or elements or adaptations of this model.

Ethical implications include the debate about whether there are reasonable grounds for expecting firms to operate on the basis of the refined model, or elements and adaptations of this model. Reasonable grounds will take into account empirical implications including those suggested above.

Ethical implications overlap with empirical implications if we consider how firms might operate in the future, based on principles generated by the firm itself or by public policy, regulation, and legislation. 